\title{
Investigating the effect of column removal on progressive collapse of buildings designed by buckling restrained braced and bending frames
}

\author{
Farzad Akbarinia $^{a}$, Yahya Adinehfar ${ }^{\mathrm{b}}$, Hadi Davashi ${ }^{\mathrm{c}}$, Dariush Jalilid, Peyman Beiranvand ${ }^{\mathrm{e}}$ \\ and Mojtaba Hosseini ${ }^{\mathrm{e}^{*}}$
}

\author{
${ }^{a}$ Department of Civil Engineering, Imam Khomeini International University, Qazvin, Iran \\ ${ }^{b}$ Department of Civil Engineering, Razi University, Kermanshah, Iran \\ ${ }^{c}$ Dezful Branch, Islamic Azad University, Iran \\ ${ }^{d}$ Faculty of Tiran Branch, Islamic Azad University, Iran \\ ${ }^{e}$ Department of Civil Engineering , Lorestan University, Khorram abad, Iran

\begin{tabular}{|c|c|}
\hline A R T I C LEI NFO & ABSTRACT \\
\hline $\begin{array}{l}\text { Article history: } \\
\text { Received } 6 \text { June, } 2017 \\
\text { Accepted } 30 \text { September } 2017 \\
\text { Available online } \\
\text { 30 September } 2017 \\
\text { Keywords: } \\
\text { Progressive collapse } \\
\text { Buckling restrained braced } \\
\text { Nonlinear static analysis } \\
\text { Removing centre and corner }\end{array}$ & $\begin{array}{l}\text { In this study, the behavior of two buildings designed with steel structures Buckling Restrained } \\
\text { Braced (BRB) and conventional bending frame was studied to analyze their strengths against } \\
\text { progressive collapse. The structures were designed and analyzed in accordance with Iranian } \\
\text { regulation No. } 2800 \text { for the design of buildings. Using nonlinear static pushover analysis, the } \\
\text { performance of the structure after removal of the center and the corner columns were } \\
\text { investigated and it was demonstrated that removing the corner column provides more critical } \\
\text { conditions for the investigated buildings. Furthermore, the use of BRB elements provides better } \\
\text { performance for the analyzed buildings due to the ability of BRB in absorbing and dissipating } \\
\text { more energy induced from the external loading sources like the earthquake. }\end{array}$ \\
\hline
\end{tabular}

columns

\section{Introduction}

Progressive damage of a structural components due to some possible sources such as fire, gas explosion, design errors and etc. can lead to overall and catastrophic failures in adjacent components and members of buildings. Since the probability of some risks such as fire, gas explosion, accidents, car accidents and bomb blast is low in buildings they are not usually considered in the design of structural and they are estimated indirectly during the design process. Generally, buildings are not designed for such loads. Thus, when the buildings are unusually subjected to these loading sources a catastrophic and overall damage might be occurred. This phenomenon can also be used for structures designed according to current design standards and regulations as well. For example, the earthquake

\footnotetext{
* Corresponding author

E-mail addresses: Peyman51471366@gmail.com (P. Beiranvand) 
can cause severe problems and even lead to the destruction of the entire structure. Therefore, it is necessary to study the effects of such loading types in integrity and stability of structures and buildings.

Buckling-Restrained Brace (BRB) is a kind of metal-yield energy-dissipation device. The core plate of a BRB, which sustains the axial tension and compression under strong earthquakes, is expected to yield before the main structural members. Because BRBs dissipate the energy induced by the earthquake through the post-yield hysteretic behavior, structural seismic responses decrease and the main structural members are kept away from the severe damage. Due to the advantages of BRBs such as stable hysteretic characteristics, simplicity in installation and low cost, they have been applied extensively in many building structures as well as bridges in Japan, North America and China (Uang et al., 2004; JIUN-WEI, 2004; Xie, 2005; Luo et al., 2010; Chen et al., 2008; Crowder et al., 2004).

There are different strategies for preventing progressive collapse and damage in the structures and buildings. Accident Control Strategy, which aims to protect the structure against events that can lead to progressive collapse of structures. Indirect plan strategy, which directly estimates the ability of structure against progressive collapse and decreasing the damage. Key element strategy and the alternative load route strategy are to name a few. For example, by applying the alternative load route strategy which was employed first time by Crawford (2002), it can be observed that the use of side plate and Truss members can play a significant role in increasing the resistance of structures against progressive collapse.

The guidelines of United States Department of Defence (DoD) and General Service Administration (GSA) suggest the sudden removal of column as the primary method against progressive collapse (Dalton et al., 2009; GSA, 2013; Kim \& Kim, 2009). In these regulations the structure is designed based on the equivalent static load and the main objective is to redistribution of gravity loads after removing the columns. Hosseini et al. (2016) studied the effect of column location and bracing on progressive collapse of steel structures. They concluded that the roof lateral displacements will reduce in both corner and middle columns but this reduction is more pronounced for middle column elimination. Also, using buckling restrained brace (BRB) they increased the shear-force and bearing capacity of non-elastic deformations and the onset of plastic deformation which lead to increase in the coefficient of structure plasticity. In recent decades, a number of researches have been conducted on designing and using new types of braces. These bracing BRBs have similar behaviour under tension and compression. Hence, they have the ability of high energy absorbing and are often known as hysteretic damper. This type of bracing usually consists of a steel core surrounded by steel sheath or other materials inside the pod filled with a kind of mortar (as shown in Fig.1)

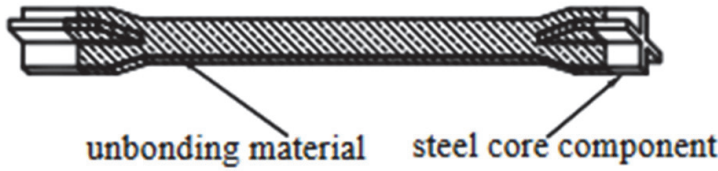

(a)

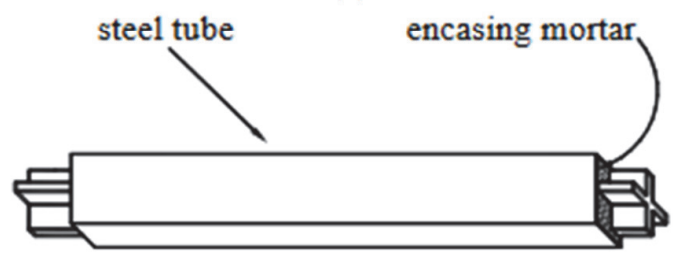

(b)

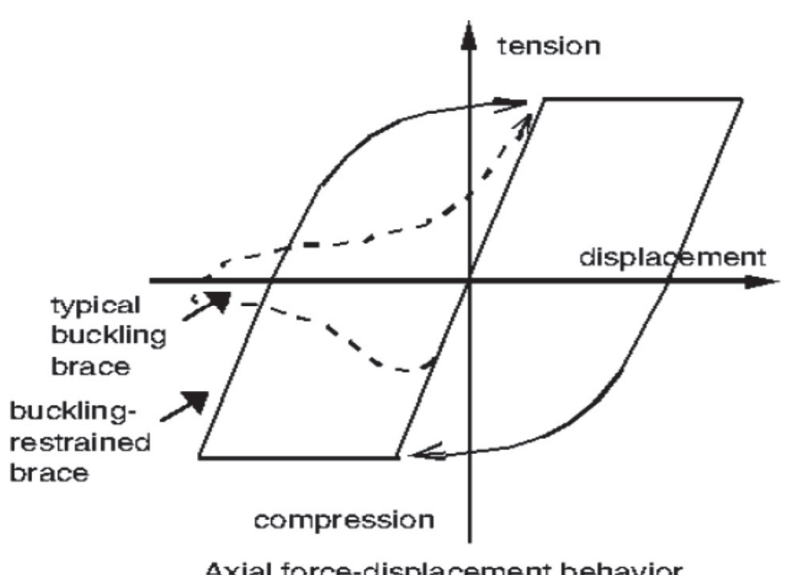

Axial force-displacement behavior

Fig.1. Schematic behaviour of buckling restrained brace (Izzuddin et al., 2007) 
In this study, the progressive collapse of two steel structures with Buckling Restrained Braced and bending frame is investigated in accordance with Iranian National Building Regulations (i.e. Sections 10 and 6 of regulation 2800). Then analysis of structural behaviour due to removal of the pillars in the lower level frame was performed and the sensitivity of progressive failure behaviour and also the load factors were determined.

\section{Nonlinear Static Analysis Pushover}

Pushover analysis of a nonlinear static analysis under lateral loads is important in structural designs especially to protect the buildings against earthquake loads. Such analysis is based on the identification of important characteristic parameters including lateral deflections and relative deformations of the members and joints. Analytical methods available for performance-based design and seismic retrofitting of structures are mainly based on nonlinear static analysis. The reason for using this type of analysis is its high speed, simplicity and accuracy of results. This procedure is a series of stepwise analyses in which reduction of member stiffness due to the effect of loading on the plastic joint at each step is considered for the next step. In this way, lateral load of earthquake with a specified pattern is increasingly applied to the structure until the displacement of a control point reaches a certain value which is called the "target displacement" that corresponds to the onset of structural collapse (Clark et al., 1999). After removing the column in each step of the analysis, the vertical displacement at the place of column due to the applied loads is recorded and finally, the ratio of balance or equivalent load over the total gravity load is defined as the load factor. Among the columns placed at different positions, the greatest potential for progressive collapse is related to that column in which has the lowest load factor after removing the column (Deulkar et al., 2010).

\section{Design and Analysis}

In this study, a three-storey building reinforced with BRB which has three spans of $5 \mathrm{~m}$ in length (as shown in Fig. 2) was designed for pushover analysis by software SAP2000 according to the instructions of FEMA-356 (Federal Emergency Management Agency, 2000). Dead load of $5 \mathrm{kN} / \mathrm{m}^{2}$, roof live load of $5.1 \mathrm{kN} / \mathrm{m}^{2}$, storey live load of $2 \mathrm{kN} / \mathrm{m}^{2}$, side wall load of $1.2 \mathrm{kN} / \mathrm{m}$ and dome roof load of $74.0 \mathrm{kN} / \mathrm{m}$ was applied to the analyses.

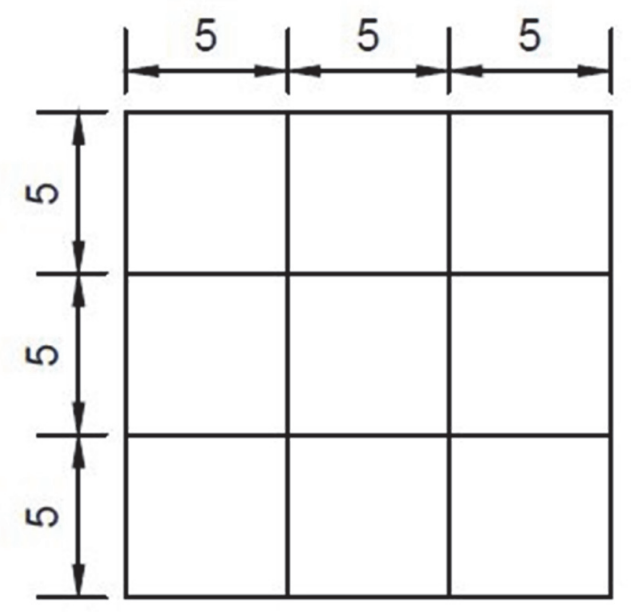

Fig. 2. Schematic plan for the investigated Building (dimensions are in meter)

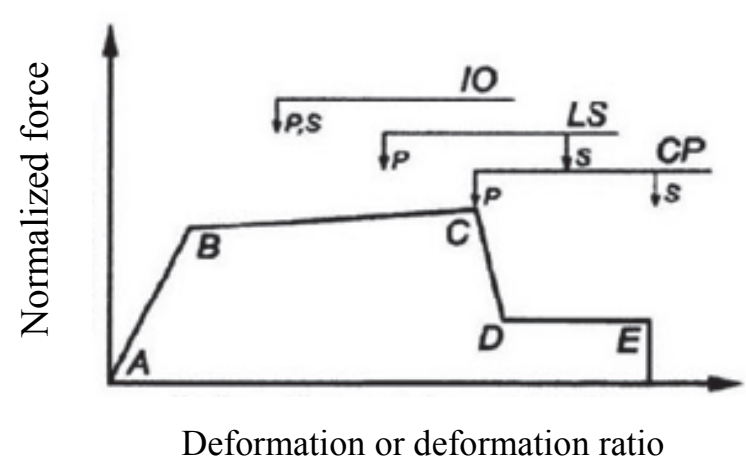

Fig. 3 Bar graph based on the movement in steel elements (FEMA-356, 2000) 
All plastic joints in the model were defined based on the rules of FEMA-356 and load levels and acceptance criteria presented in Fig. 3. In order to define the non-linear behaviour of members with controlled deformation, some numerical analyses were performed on buildings with and without BRB reinforced structures. The strain hardening behaviour was also considered for the members.

For performing the nonlinear static analyses and according to the procedures mentioned in the progressive collapse (GSA, 2013), the load applied to the structure can be determined according to the following equation:

$$
\left.G_{N}=\Omega_{N}(1.2 D+0.5 \text { or } 0.25 S)\right) \text {, }
$$

where $L$ is distributed surface load, $D$ presents the live load and $S$ represents the snow load. $\Omega_{\mathrm{N}}$ for the steel frames is determined from to the following equation:

$$
\Omega_{N}=1.08+\frac{0.76}{\left(\theta_{\operatorname{Pra}} / \theta_{y}\right)+0.83},
$$

in which $\theta_{\mathrm{Pra}}$ is the amount of plastic rotation for life safety and $\theta_{\mathrm{y}}$ is the rotation at the onset of yielding. In this research $\Omega_{\mathrm{N}}$ value for structures with and without BRB frame was obtained approximately 1.18 and 1.21, respectively. For applying the structural loading in the static analyses of the investigated building, the regulations of GSA 2013 was considered as presented in Fig. 4.

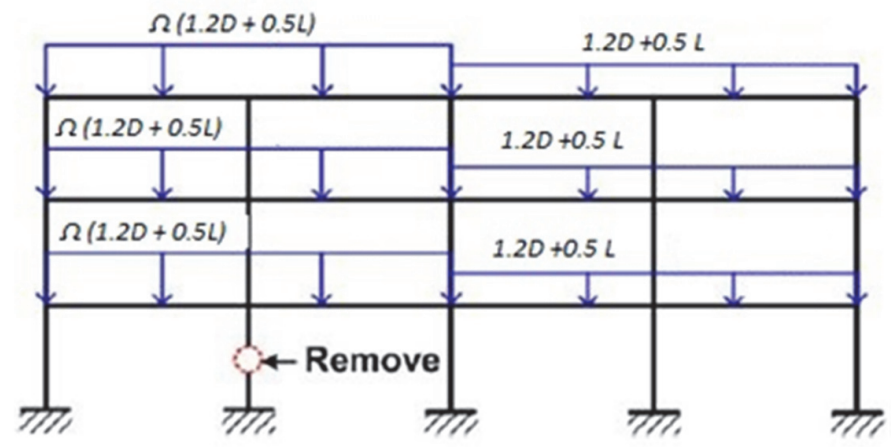

Fig. 4. Analysis of static loading for the considered building

\section{Results and Discussion}

Fig. 5 and Fig. 6 present the effects of removing centre and corner columns on the load factor of bending frame in the analysed structure.

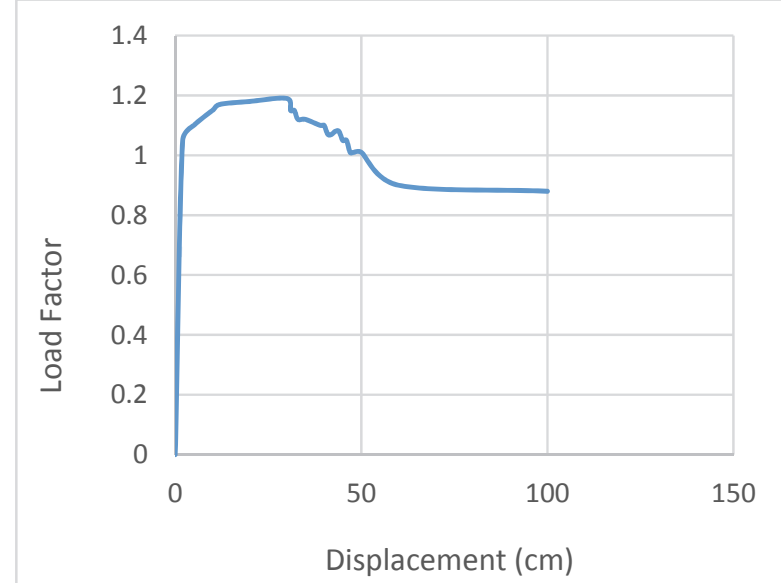

Fig. 5. Effect of removing the centre column on load factor of the bending frame in the analysed structure

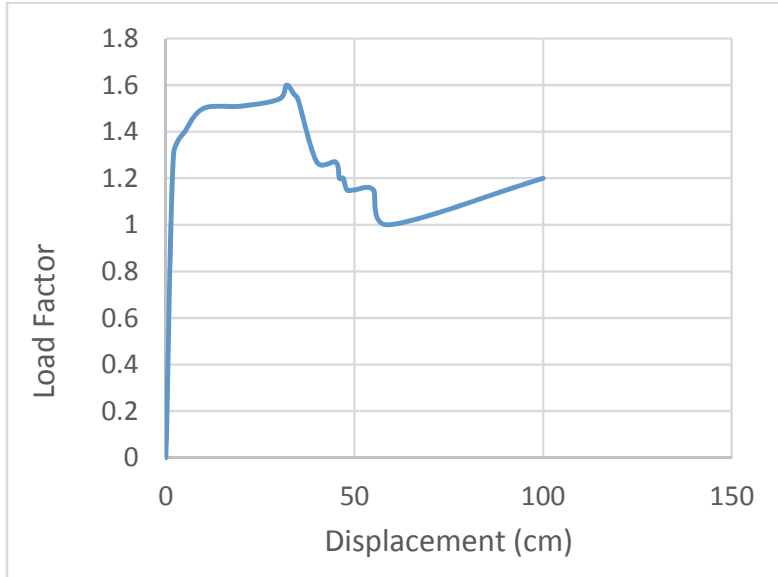

Fig. 6. Effect of removing the corner column on load factor of the bending frame in the analysed structure 
Figs. 7 and 8 also show the effects of removing the same columns but for the structure reinforced with BRB components. Based on these figures, the corner column provides more critical conditions than the centre column since this case has lower load factor in comparison with the centred one. Moreover, comparison of these figures demonstrates that adding the BRB can increase the load factor and consequently reduce the susceptibility of structure for progressive collapse. Indeed, in this case the area below the load factor-displacement curve in the linear regime becomes more showing higher ductility and energy absorption of structures reinforced with BRB.

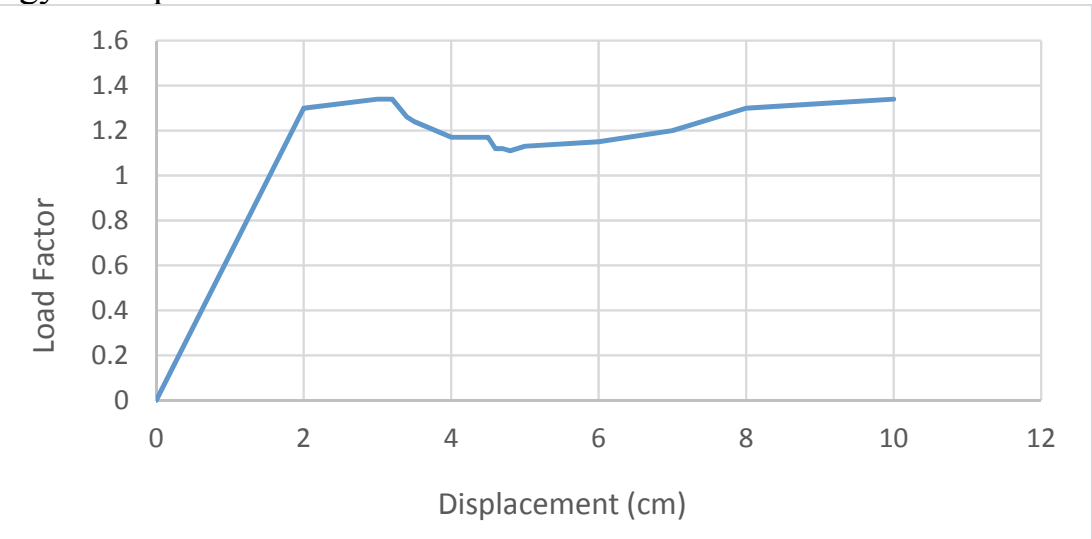

Fig.7. Effect of removing centre column on load factor of the bending frame in the analysed structure reinforced with BRB

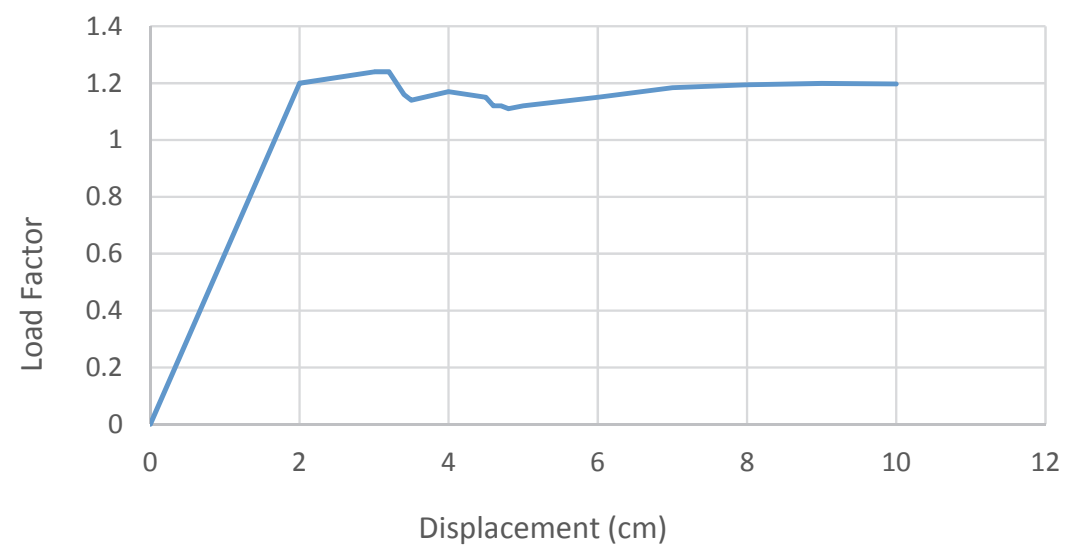

Fig. 8. Effect of removing corner column on load factor of the bending frame in the analysed structure reinforced with BRB

In addition, Table 1 and Table 2 present the lateral displacement of roof in the investigated buildings with and without BRB obtained from the static analyses. Again it is seen from these two tables that the highest roof lateral displacements are obtained by removing the corner column, demonstrating the higher risk of progressive collapse for this case. Furthermore, the lateral displacement in the BRB case is smaller than the building designed by the conventional bending frame.

Table 1. Roof lateral displacement in the structure designed with bending frame and after removing the centre and corner columns

\begin{tabular}{cc}
\hline column position & roof lateral displacement $(\mathrm{cm})$ \\
\hline Without columns removing & 15.2 \\
By removing the corner columns & 19.4 \\
By eliminating the center column & 16.2 \\
\hline
\end{tabular}

Table 2. Roof lateral displacement in the structure designed with BRB and after removing the centre and corner columns

\begin{tabular}{cc}
\hline column position & roof lateral displacement $(\mathrm{cm})$ \\
\hline Without columns removing & 14.11 \\
By removing the corner columns & 10.71 \\
By eliminating the center column & 3.43 \\
\hline
\end{tabular}




\section{Conclusion}

In this research the effect of removing centre or corner columns in a three-storey building was analysed using non-linear static analyses. It was concluded that removing the corner column provides more critical conditions for the progressive collapse of the analysed building. Meanwhile, since the BRB can act as a damper and energy absorber, using BRB reinforcement in building can increase the shear load bearing capacity and deformability of building especially under earthquake loading condition.

\section{References}

Chen, Z. Y., Ge, H. B., \& Usami, T. (2008). Analysis and design of steel bridge structures with energy absorption members. International Journal of Advanced Steel Construction, 4(3), 173-183.

Clark, P., Aiken, I., Kasai, K., Ko, E., \& Kimura, I. (1999, October). Design procedures for buildings incorporating hysteretic damping devices. In Proceedings 68th annual convention (pp. 355-371).

Council, B. S. S. (2000). Prestandard and commentary for the seismic rehabilitation of buildings. Report FEMA-356, Washington, DC.

Crawford, J. E. (2002, July). Retrofit methods to mitigate progressive collapse. In The Multihazard Mitigation Council of the National Institute of Building Sciences, Report on the July 2002 National Workshop and Recommendations for Future Effort.

Crowder, B., Stevens, D. J., \& Marchand, K. A. (2004). Design of buildings to resist progressive collapse. In Virginia Society of Professional Engineers Tidewater Chapter \& DoD Security Engineering Working Group, Short course proceedings of Security Engineering Workshop.

GSA, U. (2003). Progressive collapse analysis and design guidelines for new federal office buildings and major modernization projects. Washington, $D C$.

Hosseini, M., Beiranvand, P., Dadgar, M. R., \& Zarei, M. (2016). The effect of column location and bracing on progressive collapse of steel structures. Electronic Journal of Structural Engineering, 16, 1.

Izzuddin, B. A., Vlassis, A. G., Elghazouli, A. Y., \& Nethercot, D. A. (2007). Assessment of progressive collapse in multi-storey buildings.

JIUN-WEI, L. A. I. (2004). Research and Application of Buckling Restrained Braces in Taiwan.

Kim, J., \& Kim, T. (2009). Assessment of progressive collapse-resisting capacity of steel moment frames. Journal of Constructional Steel Research, 65(1), 169-179.

Luo, X. Q., Ge, H. B., \& Usami, T. (2010). Dynamic numerical simulation of steel frame-typed piers installed with SMA damping devices based on multi-linear one dimensional constitutive model. Advanced Steel Construction, 6(2), 722-741.

SAP2000 Advanced 14.1.0 (1995). Structural Analysis Program. Computer and Structure. Inc. (CSI), University Berkeley, CA.

Uang, C. M., Nakashima, M., \& Tsai, K. C. (2004). Research and application of buckling-restrained braced frames. International Journal of Steel Structures, 4(4), 301-313.

Xie, Q. (2005). State of the art of buckling-restrained braces in Asia. Journal of constructional steel research, 61(6), 727-748.

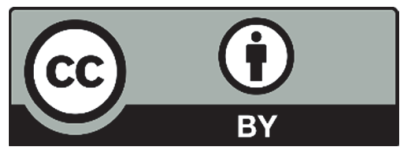

(C) 2017 by the authors; licensee Growing Science, Canada. This is an open access article distributed under the terms and conditions of the Creative Commons Attribution (CC-BY) license (http://creativecommons.org/licenses/by/4.0/). 